\title{
ANALISIS KESESUAIAN KOMPETENSI DASAR DENGAN PEMBELAJARAN BERBASIS MASALAH
}

\author{
${ }^{1)}$ Sahriani, ${ }^{2)}$ Pariabti Palloan, ${ }^{3)}$ Aisyah Azis \\ ${ }^{1)}$ SMA Negeri 21 Makasar, ${ }^{2,3)}$ Universitas Negeri Makassar \\ Kampus UNM Parangtambung Jln. Daeng Tata Raya, Makassar, 90224 \\ ${ }^{1)}$ e-mail : sahrianirafi@gmail.com
}

\begin{abstract}
Abstrak. Penelitian ini adalah penelitian kualitatif yang bertujuan untuk mengetahui kesesuaian kompetensi dasar dengan pembelajaran berbasis masalah. Penelitian ini dilaksanakan di SMA Negeri 21 Makassar. Data hasil penelitian diperoleh dengan cara melakukan observasi partisipan dan wawancara selanjutnya dianalisis secara deskriptif kualitatif. Berdasarkan hasil analisis diperoleh dari 11 kompetensi dasar materi fisika kelas X dengan 31 kali pertemuan terdapat 29 kali pertemuan yang dapat menggunakan pembelajaran berbasis masalah ditinjau dari fase-1 yaitu orientasi siswa kepada masalah.
\end{abstract}

\section{Kata kunci : Kompetensi Dasar, Pembelajaran Berbasis Masalah}

\begin{abstract}
This research is a qualitative research which aims to determine the suitability of basic competencies with problem-based learning. This research in was conducted SMA Negeri 21 Makassar. Data of research result is obtained by doing participant observation and interview then analyzed by descriptive qualitative. Based on the results of the analysis obtained from 11 basic competencies of class X physics material with 31 meetings there were 29 meetings that could use problem-based learning in terms of phase-1 namely the student's orientation to the problem.
\end{abstract}

Keywords : Basic Competencies, Problem Based Learning.

\section{PENDAHULUAN}

Kurikulum 2013 dikembangkan dengan tujuan mewujudkan pendidikan nasional, yaitu: Berkembangnya potensi peserta didik agar menjadi manusia yang beriman dan bertakwa kepada Tuhan Yang Maha Esa, berahlak mulia, berilmu, cakap, kreatif, mandiri, dan menjadi warga Negara yang demokratis serta bertanggung jawab". Penerapan kurikulum 2013 memerlukan perubahan paradigma pembelajaran, dimana peserta didik dilatih untuk belajar mengobservasi, mengajukan pertanyaan, mengumpulkan data, menganalisis (mengasosiasikan) data, dan mengkomunikasikan hasil belajar yang disebut pendekatan saintifik. (Kementrian Pendidikan dan Kebudayan: 2016).

Fisika merupakan salah satu cabang sains yang mendasari perkembangan teknologi maju dan konsep hidup harmonis dengan alam. Sebagai ilmu yang mempelajari fenomena alam, fisika juga memberikan pelajaran yang baik kepada manusia untuk hidup selaras berdasarkan hukum alam (BSNP 2006). Pembelajaran fisika merupakan sarana untuk menumbuh kembangkan kemampuan berpikir terutama dalam menyelesaikan permasalahan dalam kehidupan sehari-hari serta lebih menekankan pada pendekatan keterampilan proses yang terintegrasi pendekatan saintifik. Karena hal tersebut, diperlukan kegiatan pembelajaran yang dapat mengaitkan masalah dunia nyata dengan kajian ilmu fisika.

$$
\text { Pembelajaran berbasis masalah }
$$

(problembased learning) menurut teori konstruktivisme, siswa belajar mengkonstruksi pengetahuannya melalui interaksi dengan lingkungannya. Pembelajaran berbasis masalah (PBL) dapat membuat siswa belajar melalui upaya permasalahan dunia nyata (real world problem) secara terstruktur untuk mengkontruksi pengetahuan siswa. pembelajaran ini menuntut siswa untuk aktif melakukan penyelidikan dalam menyelesaikan permasalahan dan guru berperan 
sebagai fasilitator atau pembimbing (Ridwan, 2015).

Setiap jenjang pendidikan pasti ada standar kompetensi, kompetensi dasar, dan indikator karena untuk mengetahui materi apa saja yang akan dipelajari dan tujuan apa saja yang harus dicapai sehingga mudah karena terarah dan merupakan program yang telah terstruktur di sekolah. Standar kompetensi, kompetensi dasar, dan indikator dapat mengetahui kemampuan, keterampilan dan sikap peserta didik sehingga secara spesifik dapat dijadikan untuk menilai ketercapaian hasil pembelajaran dan juga dijadikan tolak ukur sejauh mana penguasaan siswa terhadap suatu pokok bahasan atau mata pelajaran tertentu.

Berdasarkan hasil observasi awal dan diskusi yang dilakukan oleh peneliti dan peserta didik di SMAN 21 Makassar selama 12 november 2017- 9 april 2018 diperoleh bahwa: 1) sekolah tersebut menggunakan kurikulum 2013, 2) proses pembelajaran di sekolah tersebut menggunakan berbagai macam pembelajaran berdasarkan karakteristik siswa, 2) hasil belajar yang berada pada kategori sedang, 3) peserta didik sangat tertarik dengan permasalahan tentang fisika dalam kehidupan sehari-hari. Kemudian dilanjutkan observasi kedua yang dilakukan peneliti selama 16 april-24 mei 2018, pendidik membawakan 2 Kompetensi Dasar yaitu KD 3.10. Menerapkan konsep momentum dan impuls, serta hukum kekekalan momentum dalam kehidupan seharihari, dan KD 3.11. Menganalisis hubungan antara gaya dan getaran dalam kehidupan sehari-hari. Dalam proses pembelajaran menggunakan pembelajaran berbasis masalah pada kelas $\mathrm{X}$ MIPA 1 dan $\mathrm{X}$ MIPA 2, pembelajaran konvensional (Tanya jawab dan diskusi) pada kelas X MIPA 3, X MIPA 4, X MIPA 5, dan X
MIPA 6. Peneliti lebih memfokuskan pada pembelajaran yang berlangsung di kelas X MIPA 1 dan X MIPA 3, peserta didik kelas X MIPA 1 menjadi lebih memahami penerapan fisika dalam kehidupan sehari-hari dengan melakukan praktikum di laboratorium dan diperoleh bahwa hasil belajar fisika kelas X MIPA 1 berada pada kategori tinggi dengan persentase $74,3 \%$ dan kelas $\mathrm{X}$ MIPA 3 berada pada kategori sedang dengan persentase $50 \%$.

Kerangka pengembangan Kompetensi Dasar (KD) Ilmu Pengetahuan Alam mengacu pada Kompetensi Inti (KI) sebagai unsur pengorganisasian KD secara vertikal dan horizontal. Kompetensi inti terdiri dari 4 (empat) aspek, yaitu: KI-1 (sikap dan spiritual), KI-2 (sikap sosial), KI-3 pengetahuan, dan KI-4 (keterampilan). KD sikap spiritual dan KD sikap sosial pada mata pelajaran ilmu pengetahuan alam tidak dirumuskan, tetapi hasil pembelajaran tidak langsung (indirect teaching) dari pengetahuan dan keterampilan, sehingga perlu direncanakan pengembangannya. Sangat penting sekali adanya analisis kompetensi dasar untuk mengetahui kesesuaian penggunaan pembelajaran berbasis masalah karena sebagai patokan dalam proses pembelajaran untuk mencapai tujuan pembelajaran.

Berdasarkan tujuan penerapan Kurikulum 2013, Kurikulum 2013 diterapkan bukan sekedar update pengetahuan dan keterampilan saja. Kurikulum 2013 diterapkan untuk menyiapkan siswa agar memiliki kompetensi baik sikap spiritual, sikap sosial, pengetahuan dan keterampilan agar nantinya unggul dalam persaingan global abad 21 ini. Keunggulan ini ditunjang dengan pengembangan keterampilan abad 21 seperti critical thinking, creative thinking, collaborating dan communicating $\left(\begin{array}{ll}4 & \mathrm{C}\end{array}\right)$. 
Keunggulan-keunggulan ini sudah dicanangkan dan dirumuskan dalam Standar Kompetensi Lulusan (SKL).

Berdasarkan uraian latar belakang tersebut di atas maka peneliti mengajukan judul penelitian "Analisis Kesesuaian Kompetensi Dasar dengan Pembelajaran Berbasis Masalah".

\section{METODE}

Penelitian ini merupakan penelitian pendekatan kualitatif dengan jenis penelitian hermeneutik. Pelaksanaan penelitian ini dilakukan di SMA Negeri 21 Makassar. Sumber data dalam penelitian ini adalah Silabus Mata Pelajaran Sekolah Menengah Atas/ Madrasah Aliyah (SMA/MA), sintaks pembelajaran berbasis masalah menurut Arends, dan guru fisika SMAN 21 Makassar. Instrument utama dalam penelitian ini adalah peneliti sendiri. Teknik pengumpulan data yaitu teknik observasi, teknik wawancara, dan teknik dokumentasi. Teknik analisis data menggunakan model Miles dan Huberman yaitu: reduksi data, display data, dan penarikan kesimpulan dan verifikasi. Serta untuk menguji keabsahan data dilakukan kegiatan FGD (Forum Group Discussion).

\section{HASIL DAN PEMBAHASAN}

Fokus penelitian ini adalah kesesuaian kompetensi dasar (KD) fisika kelas $\mathrm{X}$ dengan pembelajaran berbasis masalah. Sintaks pembelajaran berbasis masalah menurut Arends (2012) yaitu: Orientasi siswa kepada masalah, Mengorganisasi siswa untuk belajar, Membimbing penyelidikan individual maupun kelompok, Mengembangkan dan menyajikan hasil karya, serta Menganalisis dan mengevaluasi proses pemecahan masalah. Dalam penelitian ini memfokuskan pada fase-1 sintaks pembelajaran berbasis masalah yaitu orientasi siswa kepada masalah. Berdasarkan hasil analisis, berikut ini disajikan dalam tabel kesesuain kompetensi dasar dengan pembelajaran berbasis masalah.

Tabel 1. Analisis Kesesuaian Kompetensi Dasar dengan Model Pembelajaran Berbasis Masalah

\begin{tabular}{|c|c|c|c|}
\hline Kompetensi Dasar & Pertemuan & Topik & $\begin{array}{c}\text { Model } \\
\text { PBL }\end{array}$ \\
\hline $\begin{array}{l}\text { 3.1 menjelaskan hakikat ilmu } \\
\text { fisika dan perannya } \\
\text { dalam kehidupan, } \\
\text { metode ilmiah, dan }\end{array}$ & 1 & $\begin{array}{l}\text { 1. Hakikat dan cabang } \\
\text { ilmu fisika } \\
\text { 2. Metode ilmiah }\end{array}$ & $\mathrm{Ya}$ \\
\hline $\begin{array}{l}\text { keselamatan kerja di } \\
\text { laboratorium }\end{array}$ & 2 & $\begin{array}{l}\text { 3. keselematan kerja } \\
\text { Laboratorium fisika }\end{array}$ & Ya \\
\hline $\begin{array}{l}4.1 \text { membuat prosedur kerja } \\
\text { ilmiah dan keselamatan } \\
\text { kerja misalnya pada } \\
\text { pengukuran kalor }\end{array}$ & & $\begin{array}{l}\text { dan prinsip } \\
\text { 4. } \\
\text { Peranan fisika } \\
\text { dalam kehidupan }\end{array}$ & \\
\hline
\end{tabular}




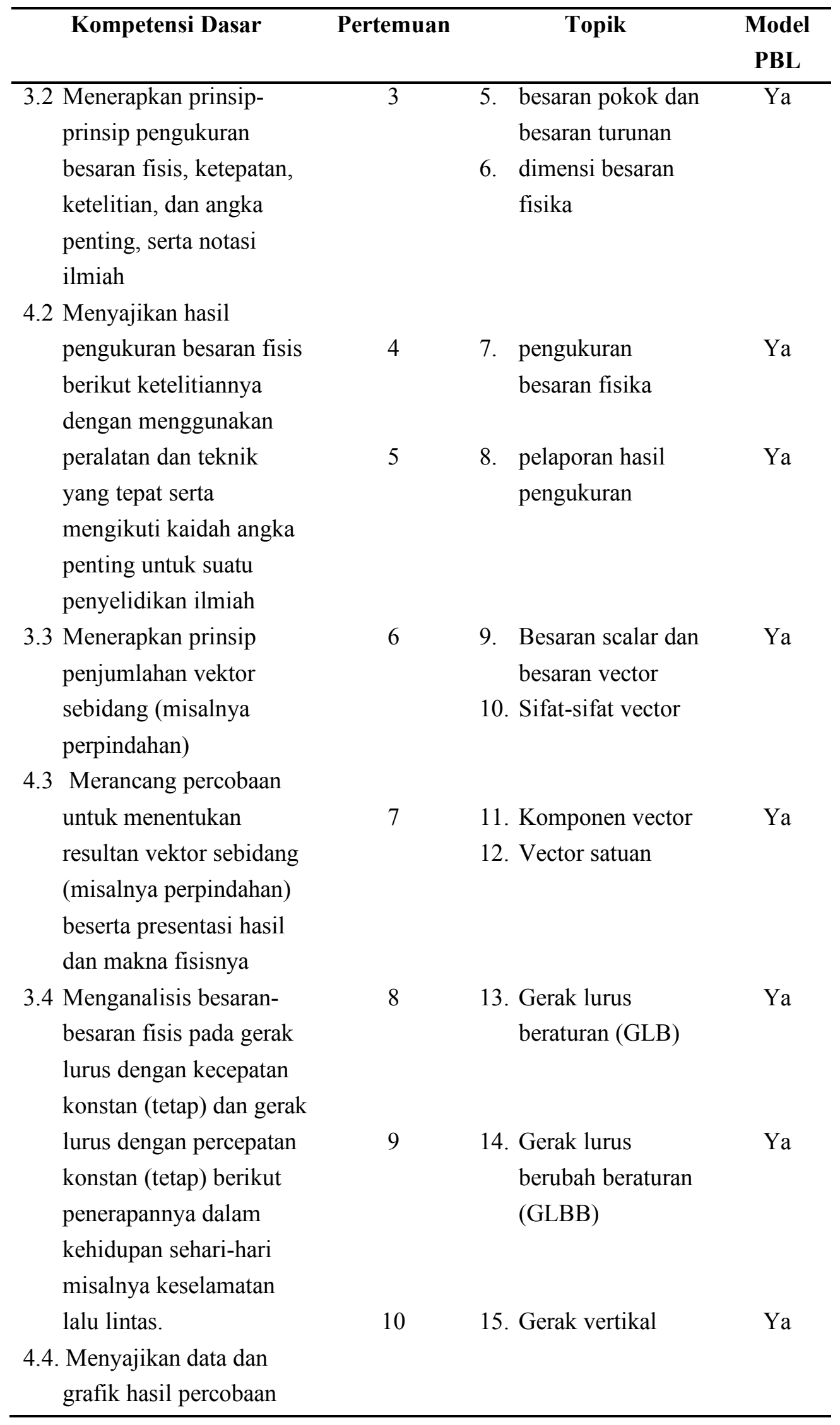




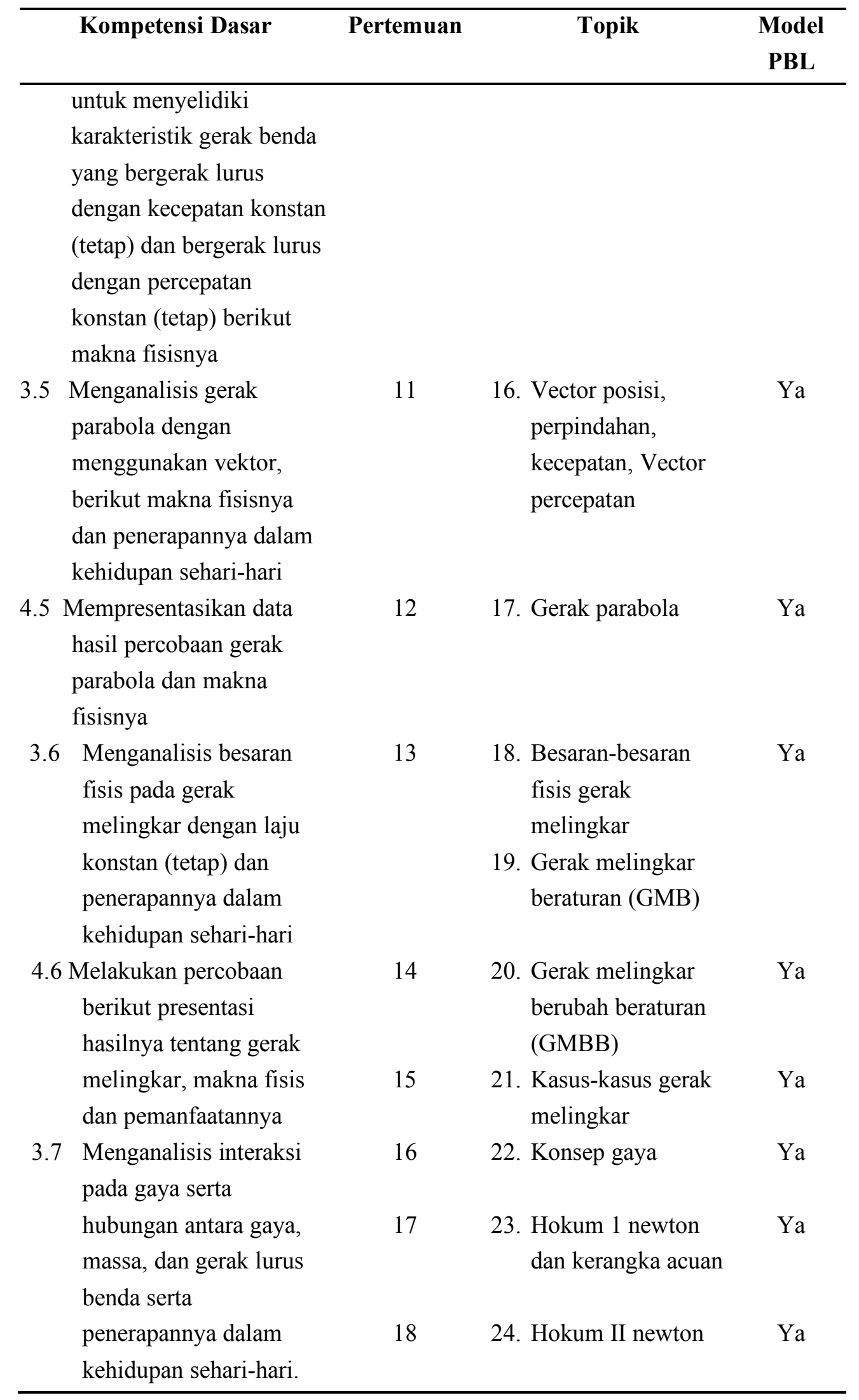




\begin{tabular}{|c|c|c|c|c|}
\hline & Kompetensi Dasar & Pertemuan & Topik & $\begin{array}{c}\text { Model } \\
\text { PBL }\end{array}$ \\
\hline 4.7 & $\begin{array}{l}\text { Melakukan percobaan } \\
\text { berikut presentasi } \\
\text { hasilnya terkait gaya } \\
\text { serta hubungan gaya, } \\
\text { massa, dan percepatan } \\
\text { dalam gerak lurus benda } \\
\text { dengan menerapkan } \\
\text { metode ilmiah }\end{array}$ & 19 & 25. Hokum III Newton & Ya \\
\hline 3.8 & $\begin{array}{l}\text { Menganalisis } \\
\text { keteraturan gerak planet } \\
\text { dan tata surya } \\
\text { berdasarkan hukum- } \\
\text { hukum Newto }\end{array}$ & 20 & $\begin{array}{l}\text { 26. Gaya gravitasi } \\
\text { 27. Medan gravitasi } \\
\text { dan percepatan } \\
\text { gravitasi }\end{array}$ & Ya \\
\hline 4.8 & $\begin{array}{l}\text { Menyajikan karya } \\
\text { mengenai gerak satelit } \\
\text { buatan yang mengorbit } \\
\text { bumi, pemanfaatan dan } \\
\text { dampak yang } \\
\text { ditimbulkannya dari } \\
\text { penelusuran berbagai } \\
\text { sumber informasi }\end{array}$ & 22 & $\begin{array}{l}\text { 29. Hokum keppler } \\
\text { 30. Gerak planet dan } \\
\text { gerak satelit }\end{array}$ & Tidak \\
\hline 3.9 & $\begin{array}{l}\text { Menganalisis konsep } \\
\text { energi, usaha (kerja), } \\
\text { hubungan usaha (kerja) } \\
\text { dan perubahan energi, } \\
\text { hukum kekekalan } \\
\text { energi, serta } \\
\text { penerapannya dalam } \\
\text { peristiwa sehari-hari }\end{array}$ & 24 & $\begin{array}{l}\text { 33. Energy potensial } \\
\text { 34. Energy potensial } \\
\text { elastic }\end{array}$ & Ya \\
\hline & $\begin{array}{l}\text { Menerapkan metode } \\
\text { ilmiah untuk mengajukan } \\
\text { gagasan penyelesaian } \\
\text { masalah gerak dalam } \\
\text { kehidupan sehari-hari, } \\
\text { yang berkaitan dengan } \\
\text { konsep energy, usaha }\end{array}$ & 25 & $\begin{array}{l}\text { 35. Hubungan usaha } \\
\text { dan energy } \\
\text { 36. Hokum kekekalan } \\
\text { energy mekanik } \\
\text { 37. Daya }\end{array}$ & $\mathrm{Ya}$ \\
\hline
\end{tabular}




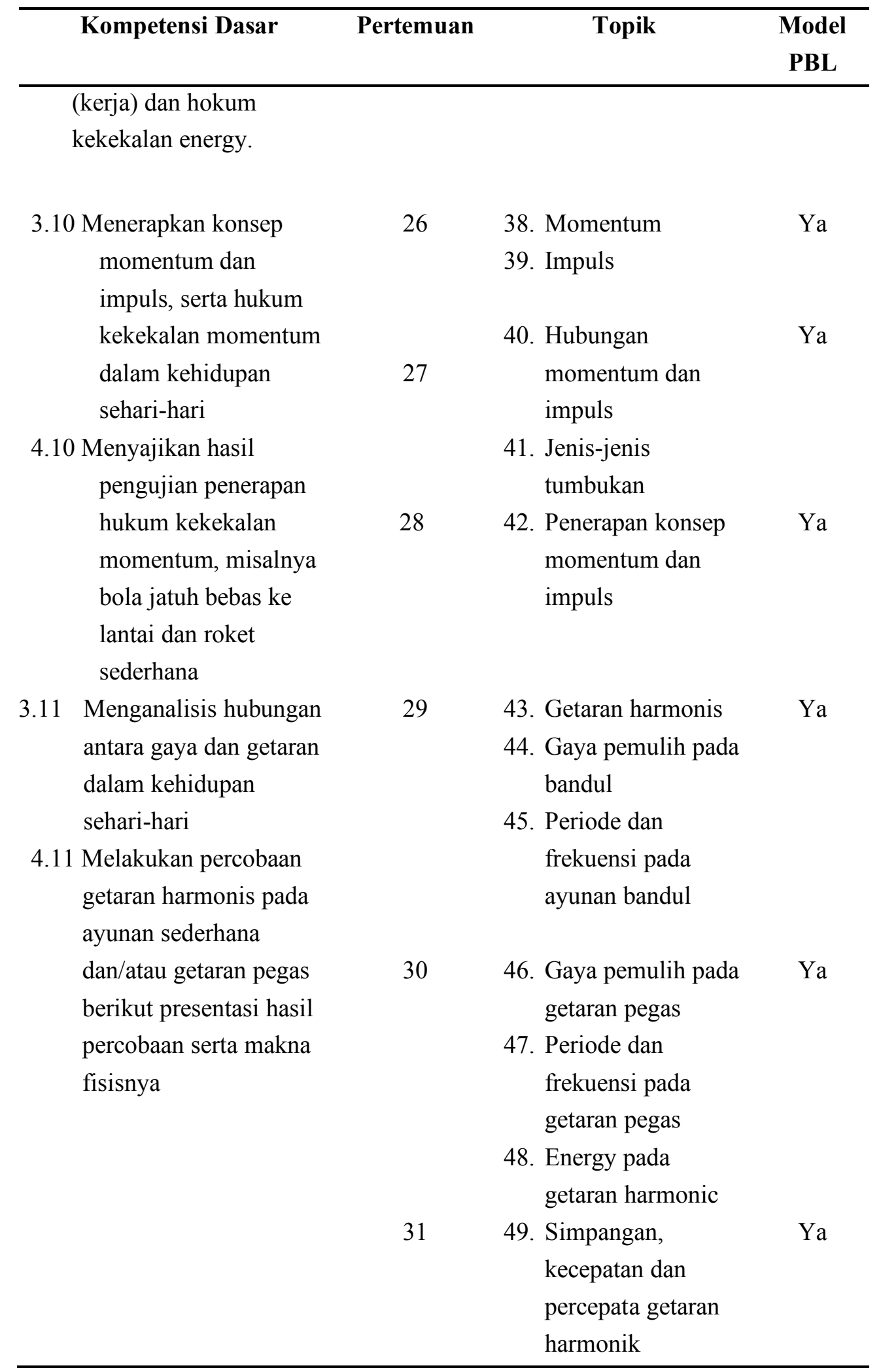


Berdasarkan data dari 31 pertemuan untuk membahas materi fisika kelas X SMA, terdapat 29 kali pertemuan yang dapat digunakan pembelajaran berbasis masalah ditinjau dari fase-1 yaitu: Orientasi siswa kepada masalah, pada fase ini menyajikan masalah dengan memberikan sebuah permasalahan yang sering terjadi dalam kehidupan sehari-hari, baik peristiwa tersebut di alami sendiri oleh peserta didik maupun dari peristiwa yang dialami oleh orang lain.

\section{SIMPULAN}

Berdasarkan fokus penelitian dapat disimpulkan bahwa dari 11 kompetensi dasar materi fisika kelas $\mathrm{X}$ dengan 31 kali pertemuan, terdapat 29 kali pertemuan yang dapat digunakan pembelajaran berbasis masalah ditinjau dari orientasi siswa kepada masalah. Permasalahan yang cocok untuk dibahas dalam PBL pada umumnya memiliki karateristik antara lain : (1) Realistis, umum, dan penting, (2) Cukup terbuka, (3) Kompleks-terdiri dari beberapa komponen, (4)Permasalahan mungkin terjadi secara nyata, namun disajikan secara tidak lengkap.

\section{DAFTAR RUJUKAN}

Arends, Richard I. 2012. Learning To Teach. New York. McGraw Hill

BSNP, T. 2006. Standar Isi. Jakarta. Badan

Standar Nasional Pendidikan

Kemdikbud. 2016. Kompetensi Dasar SMA/MA

Jakarta. Kementrian Pendidikan dan

Kebudayaan.

Sani, Ridwan 2015. Pembelajaran Saintifik

Untuk Implementasi Kurikulum 2013.

Jakarta. Bumi Aksara. 